\title{
Periscope
}

\section{A CASE OF MICROCEPHALY FOLLOWING EMBRYONIC ROENTGEN IRRADIATION.}

A woman, aged 33 years, was treated with Roentgen therapy for a "uterine myoma with metrorrhagia"; the hæmorrhage previously lasted ten days and nearly exsanguinated the patient. The uterus was somewhat enlarged and was thought to contain a small myoma in the right wall. The patient was not thought to be pregnant and the uterus was not explored. Four treatments were given at weekly intervals, the bleeding stopped and the patient immediately began to improve.

About one month after the last Roentgen exposure, fotal movements were felt, and a small male child was born apparently at term, weighing 3 lbs. I I ozs. Labour was precipitous. The child's head was noticed to be extremely small. According to the dates given, the embryo received its first irradiation after two and a half months of intra-uterine life, and the last treatment one month later.

The mother had three children previous to this, of normal size and development. The first died in thirteen hours supposedly from heart failure, the second and third were of superior intelligence and sound physique. One child was born two years after the birth of the one irradiated in utero and was normal both mentally and physically. There was no history of any mental taint or hereditary physical abnormality among the ancestors on either side.

The fact that, in a healthy family, a mentally defective child of mo microcephalic type was born following irradiation in the early months of intra-uterine life would seem to support the belief that the arrested mental development was the result of the irradiation. This Would suggest that in every case where the uterus is to be irradiated, curetting should be carried out, especially as carcinoma of the fundus is not infrequently associated with submucous myomata, one of the common indications for uterine irradiation in women of the childbearing age.

At the subsequent discussion a case was reported of a microcephalic child, now six years old, whose mother was also irradiated for a benign tumour during the pregnancy. Three other brothers, all orn earlier, were normal. $E_{D_{G A R}}$

A. Doll and Douglas P. Murphy (Amer. Journ. Psychiat., I 930, ix., 87 I-878).

\section{POST-VACCINATION ENCEPHALITIS.}

Three views have been put forward to explain the occurrence of phalitis following vaccination.

of (I) Some observers believe that neither the vaccine nor the virus ordinary lethargic encephalitis have any direct bearing on the 


\section{Periscope}

problem, and that a third and independent factor is responsible. There is little experimental evidence in support of this view.

(2) Levaditi and others believe that post-vaccination encephalitis differs little, if at all, from lethargic encephalitis, and that it occurs in carriers of the virus of ordinary lethargic encephalitis, either as a result of lowering of the general resistance by vaccination, or that vaccination activates the dormant virus of lethargic encephalitis in such a carrier. This view is partly based on their inabilty to produce the characteristic lesions by inoculation of the vaccine virus in animals, nor of brain emulsion from patients dead of this condition.

(3) Another group considers post-vaccination encephalitis to be a distinct disease entity caused directly by the vaccine virus and producing characteristic histological changes in the central nervous system. They claim to be able to produce identical lesions in animals by inoculating them with brain emulsions of patients; by finding vaccine virus in the brain of these animals; by noting the close similarity of the histological changes in the brain in this form of encephalitis to the changes seen in the brain of variola patients with cerebral symptoms and by recognising changes in the brain which are characteristic for post-vaccination encephalitis and quite unlike those seen in lethargic encephalitis.

All observers are agreed that the severity of the local or general reaction has no bearing, and that there is no evidence of contamination of the virus employed.

The clinical symptoms are usually ushered in abruptly about ten days after vaccination with no unusual symptom during this period of incubation, or any particular change at the vaccination wound. Headache, vomiting, fever, convulsions and somnolence are frequent, but the most important are the nervous manifestations which may resemble those seen in serous meningitis, encephalitis or in myelitis. Stiffness of the neck is common, but ocular palsy is rare. The spinal fluid is usually clear, the cells are sometimes moderately increased and the Pandy reaction is occasionally positive. The entire course lasts

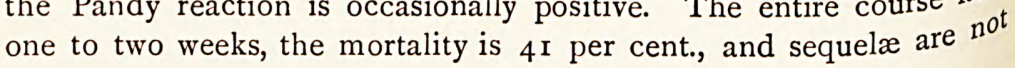
common.

A few cases show a clinical picture of tetanus with trismus, but the post-mortem changes are those of encephalitis.

One case is described here in a man, aged 23 years. The 10cal reaction was not severe, and the symptoms began eleven days after vaccination. Complete recovery took place in eight days, and $\mathrm{n}^{0}$ sequelæ occurred.

H. Wolf and Wm. A. Brams (Journ. Nerv. and Ment. Dis., I 930, lxxi., 7 74-7 I 7). 